\title{
Fine mapping of the dyskeratosis congenita locus in $\mathrm{Xq} 28$
}

\author{
S W Knight, T Vulliamy, G L Forni, D Oscier, P J Mason, I Dokal
}

\begin{abstract}
Dyskeratosis congenita (DC) is characterised by reticulate skin pigmentation, mucosal leucoplakia, and nail dystrophy. Bone marrow failure occurs in $50 \%$ of patients and is the principal cause of early mortality. In the majority of families the pattern of inheritance of DC is compatible with an $X$ linked recessive trait. The locus for the $X$ linked recessive form of DC has been linked to Xq28. We have now extended our earlier studies by investigating five families with additional Xq28 polymorphic markers; analysis of recombinantion events in these families has located the DC1 locus between GABRA3 and DXS1108, an interval of approximately $4 \mathrm{Mb}$.
\end{abstract}

( $(\mathcal{M}$ Med Genet 1996;33:993-995)

Key words: dyskeratosis congenita; X linked; Xq28.

Dyskeratosis congenita (DC) (MIM 305000) is an inherited multisystem disorder which is characterised by the early manifestion of reticulate skin pigmentation, mucosal leucoplakia, and nail dystrophy, usually below the age of 15 years. ${ }^{1}$ A variety of non-cutaneous features have been reported, including epiphora, early dental loss, and skeletal and gastrointestinal abnormalities. Bone marrow failure occurs in approximately $50 \%$ of cases and there is also a predisposition to malignancy, especially epithelial carcinomas of the gastrointestinal tract and skin. ${ }^{1}$ The finding of chromosomal rearrangements, particularly in fibroblasts, suggests that DC is a chromosomal instability disorder, ${ }^{2}$ although the evidence for an increased susceptibility to clastogenic agents is disputed. ${ }^{3}$ In the majority of reported families the inheritance of DC is compatible with an X linked recessive disorder. ${ }^{1}$ Familial and sporadic female cases of DC have been reported with possible autosomal dominant (MIM 127550) and recessive (MIM 22430) modes of inheritance, a milder clinical phenotype having been observed in the autosomal dominant cases. ${ }^{1}$ We propose to call the major X linked DC locus DC1. Analysis of polymorphic markers within the long arm of the $\mathrm{X}$ chromosome in one large pedigree assigned the $\mathrm{X}$ linked DC1 locus to $\mathrm{Xq}_{28}{ }^{4}$ and this linkage was subsequently confirmed in three other families. ${ }^{5}$ Here we present a refinement of the linkage analysis using additional polymorphic markers within Xq28, which allows the region of the DC1 locus to be delimited.

\section{Subjects and methods}

FAMILIES

A total of five families from the Dyskeratosis Congenita Registry were used in the linkage analysis; for each the inheritance of DC was consistent with an $\mathrm{X}$ linked recessive disorder (fig 1). Family 001 has been described previously and linkage to DXS52 reported, ${ }^{56}$ although this pedigree is now updated with new members and subject IV.3 confirmed as being affected. Family 007 is related to the pedigree for which linkage analysis was originally performed. ${ }^{4}$ At risk subjects were considered to be unaffected if they were over 15 years of age and without nail dystrophy, leucoplakia, or skin abnormalites or any other recognised symptoms of the disease. Male subjects below the age of 15 were classified as unknown unless definite clinical signs were ascertained by the authors. In family 002, the obligate carrier I.2 had the odd dystrophic nail on the hands and feet together with slight abnormal pigmentation around one ankle. Those people who were available for use in the linkage anlaysis are indicated with an asterisk in fig 1 .

\section{METHODS}

DNA was extracted from leucocyte pellets in the standard way. ${ }^{7}$ The primers and PCR conditions used for the following microsatellite markers were taken from the respective references DXS1113, ${ }^{8}$ DXS $1684,{ }^{9}$ GABRA $3,{ }^{10}$ and DXS1108. ${ }^{11}$ PCR products were analysed on $6 \%$ urea polyacrylamide gels after ${ }^{32} \mathrm{P}$ dCTP had been added to the reactions. The VNTR DXS52 $2^{12}$ was amplified and the products were analysed on an agarose gel. The diallelic markers $\mathrm{G} 6 \mathrm{PD}^{13}$ and $\mathrm{F} 8 \mathrm{C}^{14}$ were investigated by amplification followed by digestion with the appropriate restriction enzymes and analysis on an agarose gel. The allele frequencies for the polymorphic markers were taken from the GDB 6.0. The DC1 locus was tested assuming that the disease was an $\mathrm{X}$ linked recessive trait with an allele frequency of the affected allele of 0.001 with complete penetrance. The family linkage data were managed using the IGD/ XPED database system. ${ }^{15}$ Linkage analysis was performed using the MLINK programme of the LINKAGE package. ${ }^{16}$

\section{Results}

The pairwise linkage analysis between DC1 and each polymorphic marker resulted in a maximum lod score with DXS52 $(\mathrm{Zmax}=4.4$, $\theta=0$ ) (table 1). No linkage disequilibrium 


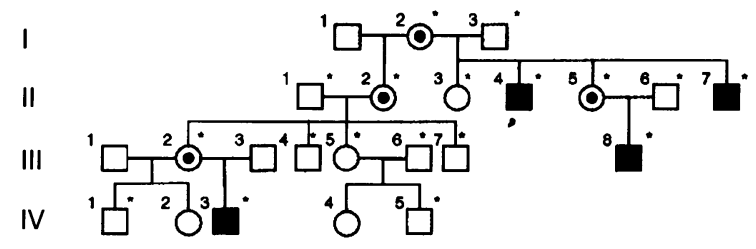

Family 001

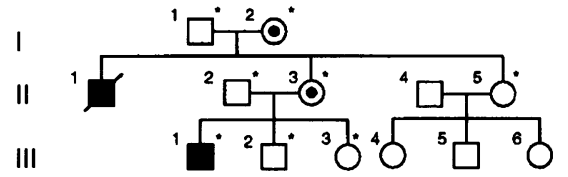

Family 005

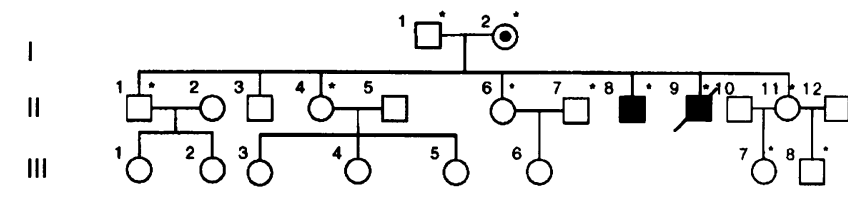

Family 002

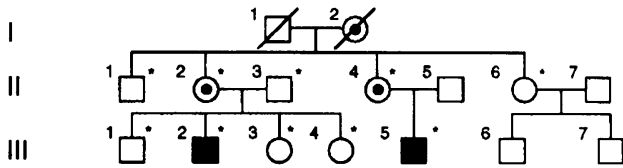

Family 006

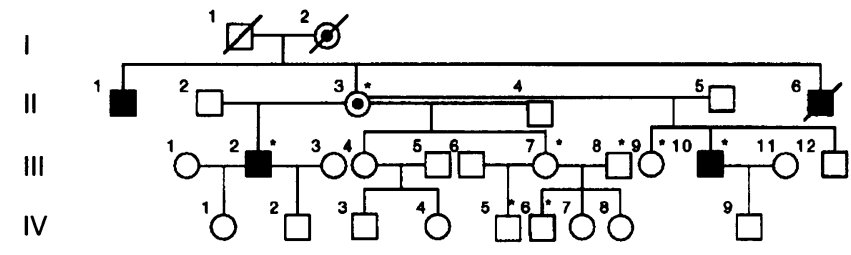

Family 007

Figure 1 Pedigrees of families with dyskeratosis congenita.

Table 1 Pairwise lod scores between DC1 and six polymorphic marker loci

\begin{tabular}{llrrrrrr}
\hline Locus & \multicolumn{7}{l}{ Recombination fraction $\theta$} \\
\cline { 2 - 8 } & 0.00 & \multicolumn{1}{l}{0.010} & \multicolumn{1}{l}{0.050} & \multicolumn{1}{l}{0.100} & 0.200 & 0.300 & 0.400 \\
\hline DXS1113 & $-\infty$ & -0.498 & 0.691 & 1.023 & 1.053 & 0.795 & 0.418 \\
DXS1684 & $-\infty$ & -2.730 & -0.803 & -0.119 & 0.328 & 0.375 & 0.244 \\
DXS52 & 4.405 & 4.327 & 4.003 & 3.577 & 2.663 & 1.690 & 0.744 \\
G6PD & 3.097 & 3.041 & 2.809 & 2.509 & 1.871 & 1.192 & 0.524 \\
F8C & 1.896 & 1.864 & 1.734 & 1.565 & 1.200 & 0.800 & 0.381 \\
DXS1108 & $-\infty$ & 1.755 & 2.215 & 2.204 & 1.835 & 1.281 & 0.637 \\
\hline
\end{tabular}

between DC1 and any DXS52 allele was observed. In family 006, three recombination events were indentified when the phase of the markers was inferred and the genotypes of the grandparents deduced (fig 2). Recombination events were inferred between DXS52 and DXS1684 in II.2 and between F8C and DXS1108 in II.4. Another recombination was observed when the GABRA3 marker was analysed in II. 2 between DXS52 and GABRA3, which enabled the centromeric boundary of the DC1 locus to be defined (fig 2). The affected subject III. 5 inherited the recombinant chromosome from his mother II.4, thus allowing for the telomeric boundary of the DC1 locus to be determined as DXS1108 (fig 2). On the basis of the genetic linkage analysis in this family we would predict that the daughter III. 3 is a carrier of the disease. In family 002, in which there is cosegregation of the disease and DXS52, one further recombinant chromosome was observed between DXS1684 and DXS52 in II.8. In this case, the GABRA3 marker was uninformative and no further refinement of the location of the DC1 locus was possible. In summary the most probable location for the DC1 locus is between GABRA3 and DXS1108.

\section{Discussion}

We report the fine genetic mapping of the $\mathrm{X}$ linked form of dyskeratosis congenita within $\mathrm{Xq} 28$. The DC1 locus is now delimited to between the polymorphic markers GABRA3 and DXS1108, a region of $4 \mathrm{Mb}$ according to the recent $\mathrm{X}$ chromosome map. ${ }^{17}$ In a report of a family showing $\mathrm{X}$ linked inheritance of $\mathrm{DC}$, there is evidence of recombination between G6PD deficiency and DC. ${ }^{18}$ This raises the possibility that the G6PD gene represents a boundary to the DC1 locus. The absence of recombinations between the marker DXS52 and dyskeratosis congenita in any reported pedigree $^{45}$ emphasises the usefulness of this marker in the identification of carriers and early diagnosis of people considered to be at risk. ${ }^{6}$

A number of candidate genes from within $\mathrm{Xq} 28$ have been investigated as the possible DC1 gene. Single strand conformational polymorphism analysis of the biglycan and p55 genes detected no mutations. ${ }^{1920}$ Sequencing of the QM gene in DC patients showed no mutations ${ }^{21}$ and no gross differences were detected in the DNAse I-like gene DNL1L from DC patients. ${ }^{223}$ The melanoma associated antigen genes (MAGE), which occur in three distinct clusters within Xq27-Xq28, have been suggested as possible candidates for the $\mathrm{DC} 1$ locus. ${ }^{24}$ This report enables the exclusion of some of the MAGE genes as candidates for the DC1 gene. However, the MAGE-2, MAGE- 


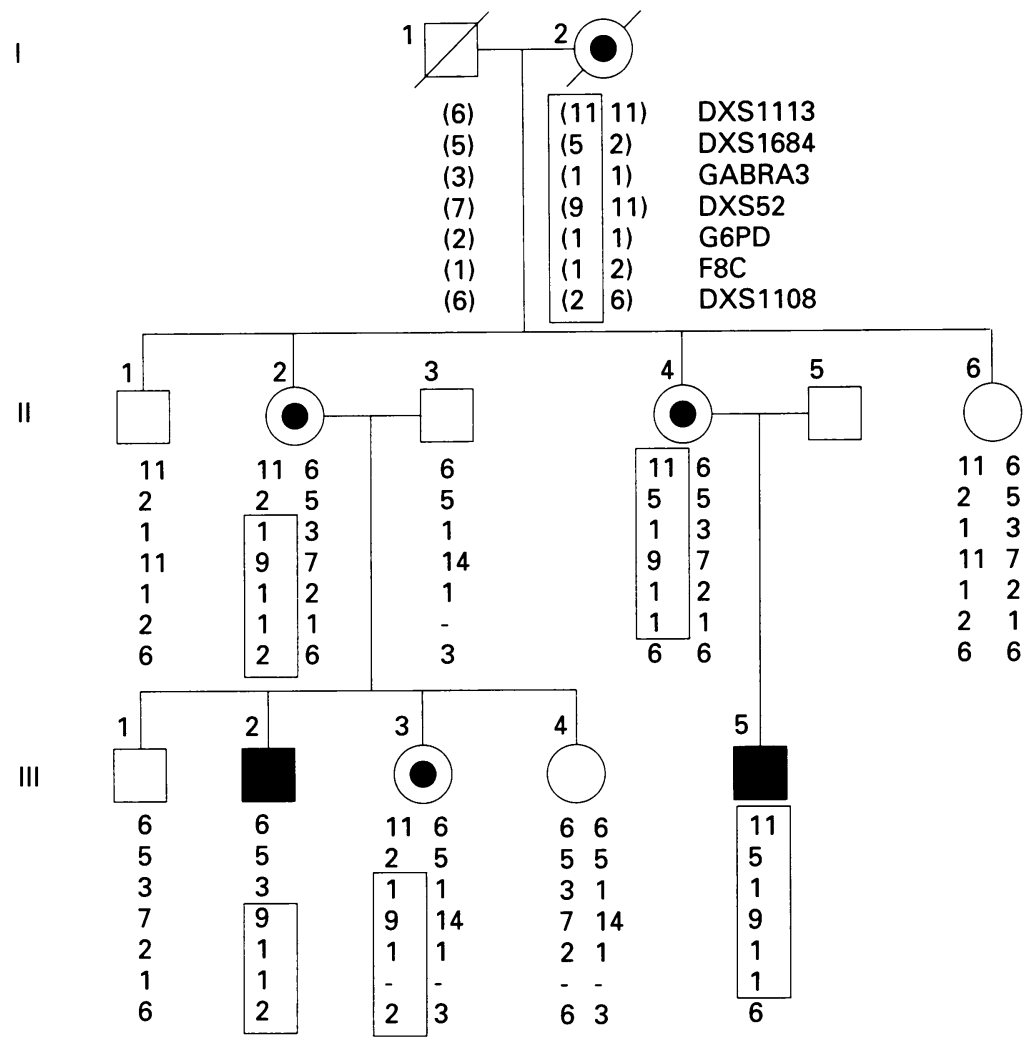

Figure 2 Pedigree of family 006 showing the haplotypes of which the phase has been inferred minimising the number of recombinations. The bracketed haplotypes of the grandparents were deduced from their offspring. The affected haplotype has been boxed.

3, MAGE-6, and MAGE-12 genes remain positional candidates. ${ }^{24}$

In conclusion, this work has enabled us to refine the location of the DC1 locus which will greatly aid the subsequent positional cloning of the DCl gene.

We wish to thank Dr J Ross (Department of Haematology, Northampton General Hospital), Dr A Copplestone (Department of Haematology, Derriford Hospital, Plymouth), and Dartment of Raeburn (Department of Clinical Genetics, City Hospital, Northampton) for providing samples. We acknowledge Faith Northampton) for providing samples. We acknowledge Faith Bellis and Maria Mukheriee for helping with the Dyskeratosis
Congenita Registry and Professor John Goldman for his support Congenita Registry and Professor John Goldman for his support
of this project. We also acknowledge the financial support of of this project. We also acknowledge the financial support of
the Medical Research Council and the resources of the UK Human Genome Mapping Project.

1 Drachtman RA, Alter BP. Dyskeratosis congenita - clinical and genetic-heterogeneity - report of a new case and review of the literature. Am $\mathcal{F}$ Pediatr Hematol Oncol 1992; 14:297-304

2 Dokal I, Luzzatto L. Dyskeratosis congenita is a chromosomal instability disorder. Leuk Lymphoma 1994;15:1-7.
3 Dokal I. Dyskeratosis congenita - an inherited bone-marrow failure syndrome. Br F Haematol 1996;92:775-9.

4 Connor JM, Gatherer D, Gray FC, Pirrit LA, Affara NA. Assignment of the gene for dyskeratosis congenita to Xq28. Hum Genet 1986;72:348-51.

5 Arngrimsson R, Dokal I, Luzzatto L, Connor JM. Dyskeratosis congenita: three additional families show linkage to a locus in Xq28. 7 Med Genet 1993;30:618-19.

6 Dokal I, Bungey J, Williamson P, Oscier D, Hows J, Luzzatto L. Dyskeratosis-congenita fibroblasts are abnormal and L. Dyskeratosis-congenita fibroblasts are abnormal and have unbalanced

7 Sykes BC. DNA in heritable disease. Lancet 1983;ii:787-9.

8 Weber C, Oudet C, Johnson S, Pilia G, Schlessinger D, Hanauer A. Dinucleotide repeat polymorphism close to IDS gene in Xq27.3-q28 (DXS1113). Hum Mol Genet 1993;2:612.

9 Dahl N, Samson F, Thomas NS, et al. X linked myotubular myopathy (MTM1) maps between DXS304 and DXS305 closely linked to the DXS455 VNTR and a new, highly informative microsatellite marker (DXS1684). $7 \mathrm{Med}$ Genet 1994;31:922-4.

10 Hicks AA, Johnson KJ, Barnard FA, Darlison MG. Dinucleotide repeat polymorphism in the human X-linked GABA A receptor alpha-3 subunit gene. Nucleic Acids Res 1991;19:4016.

11 Freije D, Helms C, Watson MS, Doniskeller H. Identification of a 2 nd pseudoautosomal region near the $\mathrm{Xq}$ and Yq telomeres. Science 1992;258:1784-7.

12 Richards B, Heilig R, Oberle I, Storioham L, Horn GT Rapid PCR analysis of the st14 (DXS52) VNTR. Nucleic Acids Res 1991;19:1944.

13 Kurdi-Haidar B, Mason PJ, Berrebi A, et al. Origin and spread of the glucose-6-phosphate-dehydrogenase varian (G6PD-mediterranean) in the middle-east. $\mathrm{Am} \mathrm{f} \mathrm{Hum}$ Genet 1990;47:1013-19.

14 Kogan SC, Doherty M, Gitschier J. An improved method for prenatal diagnosis of genetic disease by analysis of for prifiad DNA sequences. N Engl f Med 1987;317:98590 .

15 Spiridou A, Spurr NK, Bryant S. IGD/X-PED: a system for the management and graphical display of pedigree data. (In preparation.)

16 Lathrop GM, Lalouel JM, Julier C, Ott J. Strategies for multilocus linkage analysis in humans. Proc Natl Acad Sci USA 1984;81:3443-6.

17 Nelson DL, Ballabio A, Cremers F, Monaco AP, Schlessinger D. Report of the 6th international workshop on Xchromosome mapping 1995. Cytogenet Cell Genet 1995; 71:308-36.

18 Gutman A, Frumkin A, Adam A, Bloch-Shtacher, Rozenszajn LA. X-linked dyskeratosis congenita with pancytopenia. Arch Dermatol 1978;114:1667-71.

19 Das S, Metzenberg A, Pai GS, Gitschier J. Mutational analysis of the biglycan gene excludes it as a candidate analysis of the biglycan gene excludes it as a candidate keratosis-congenita, and incontinentia pigmenti. Am $\mathcal{F}$ keratosis-congenita, and in

20 Metzenberg AB, Pan Y, Das S, Pai GS, Gitschier J. Molecular evidence that the p55 gene is not responsible for either of 2 Xq28-linked disorders - Emery-Dreifuss muscular-dystrophy and dyskeratosis-congenita. $A m \mathcal{F}$ Hum Genet 1994;54:920-2.

21 Stanbridge E, Farmer A, Mills A, et al. Molecular characterization of $\mathrm{QM}$, a novel gene with properties consistent with tumor suppressor function. Cold Spring Harbor Symp Quant Biol 1994;59:573-6.

22 Parrish JE, Ciccodicola A, Wehnert M, Cox GF, Chen E Nelson DL. A muscle-specific DNAse I-like gene in Nelson DL. A muscle-specific DNAse I-like gene in
human Xq28. Hum Mol Genet 1995;4:1557-64.

23 Pergolizzi R, Appierto V, Bosetti A, Debellis G, Rovida E, Biunno I. Cloning of a gene encoding a DNAse I-like endonuclease in the human Xq28 region. Gene 1996;168 267-70.

24 Rogner UC, Wilke K, Steck E, Korn B, Poustka A. The melanoma antigen gene (MAGE) family is clustered in the chromosomal band Xq28. Genomics 1995;29:725-31. 